\title{
Is the Whole Greater Than the Sum of Its Parts?
}

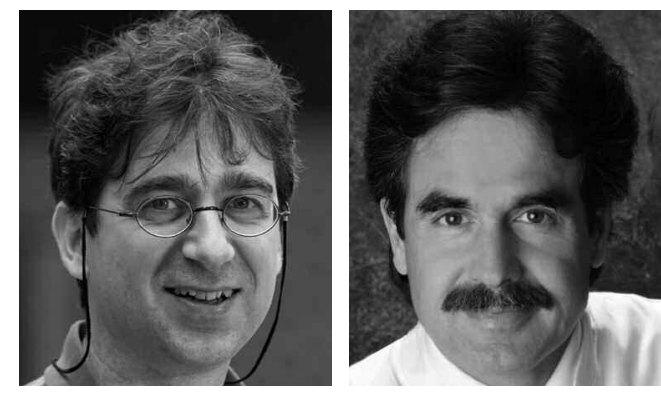

In this issue of The Journal, Rajiv Gandhi and coauthors from the Division of Orthopedic Surgery, University of Toronto, present data on patient-reported functional outcomes of 1596 patients one year after hip or knee arthroplasty as a function of preoperative metabolic abnormalities associated with the metabolic syndrome ${ }^{1}$. Their main finding is that individual metabolic abnormalities, mainly obesity, were stronger predictors of poorer functional outcomes compared with the number of metabolic abnormalities. The authors nevertheless conclude that functional outcomes are negatively affected by metabolic abnormalities, perhaps secondary to the systemic proinflammatory state ${ }^{1}$.

In recent years a large number of different studies have been performed to investigate the influence of patient-specific cofactors (i.e., sociodemographic characteristics, preoperative function and activity level, body weight, comorbidity, patient expectation) on the outcome of joint replacement ${ }^{2,3}$. Among the risk factors for metabolic syndrome, obesity in particular has been studied extensively. Although the number of studies with adequate sample size and a sufficient number of morbidly obese patients involved is still limited, more recent data seem to support the finding that obesity can have a negative effect on postoperative function $^{3,4}$ and surgical complication rates ${ }^{5,6}$. The exact mechanism is unclear, however, because obesity is not just a function of weight relative to height, but is associated with a variety of metabolic and behavioral patterns that may lead to negative outcomes. To our knowledge, no other studies have been published to date that investigate the influence of obesity together with other metabolic abnormalities that constitute what is often referred to as the metabolic syndrome $^{7}$ on outcomes after hip and knee arthroplasty.

Insulin resistance is the cornerstone of the metabolic syndrome, which is a risk factor for development of cardiovascular disease (myocardial infarction and stroke) and type 2 diabetes, beyond the risk associated with the individual metabolic abnormalities alone ${ }^{8}$. Risk factors for insulin resistance include adiposity, (lack of) fitness, and genetics ${ }^{7}$.
The metabolic syndrome can be defined as the simultaneous presence of central adiposity, low levels of HDL cholesterol and elevated levels of triglycerides, impaired fasting glucose, and hypertension ${ }^{9}$.

While subclinical systemic inflammation as assessed by high-sensitivity C-reactive protein (CRP) has been shown to be associated with pain in patients with osteoarthritis and low back pain ${ }^{10,11}$ in cross-sectional studies, it is still largely unknown whether subclinical systemic inflammation leads to a change in pain perception or whether pain leads to subclinical systemic inflammation. The authors argue that because the number of metabolic abnormalities is associated with higher levels of inflammatory markers, e.g., CRP, and the number of metabolic abnormalities is associated with poorer outcomes, that systemic inflammation might be related to functional outcomes after arthroplasty.

First, we would point out that the number of metabolic abnormalities is a very crude measure of subclinical inflammation. More importantly, the finding that individual abnormalities predict functional outcomes better than the number of metabolic abnormalities speaks against this hypothesis ${ }^{12}$. And finally, even if subclinical systemic inflammation were associated with poorer functional outcomes, we would still need to know whether this association is independent of the metabolic abnormalities.

Because the whole is not greater than the sum of its parts, we disagree that the data of Gandhi and coauthors support the hypothesis that systemic inflammation or the metabolic syndrome as defined by the presence of several metabolic abnormalities plays an important role for functional outcomes after hip or knee arthroplasty.

We nevertheless think that their article ${ }^{1}$ is valuable. It highlights the need for collecting data on clinically relevant - including patient-reported - short, intermediate, and longterm outcomes after arthroplasty, in order (1) to investigate what predicts clinically relevant outcomes ${ }^{13}$; and (2) to improve those outcomes based on the best available evidence. Ideally, such data would include not only data on

See Metabolic syndrome and the functional outcomes of hip and knee arthroplasty, page 1917 
patients but also data on the type of surgery performed, the medical device implanted, postoperative in-hospital treatments and procedures, rehabilitation measures ${ }^{14}$, and activities ${ }^{15}$ during followup. Datasets would need to be large; and patients enrolled, surgeons, and devices implanted would need to be diverse enough to allow us to predict outcomes both as a function of patient and procedure characteristics as well as within specific subgroups defined, e.g., by age, preoperative function, and obesity. Followup for clinically relevant outcomes, including self-reported performance ${ }^{16}$, would need to be both as regular and as complete as possible to avoid selection biases. The authors report data from an ongoing registry that routinely collects important pieces of this information combined with patient-reported outcomes for a reasonable proportion (83.3\%) of all those with arthroplasty after one year.

When assessing the causal influence of metabolic abnormalities on functional outcomes, it is very important to adequately control for confounding by factors leading to metabolic abnormalities and potentially poorer functional outcomes ${ }^{17,18,19}$. The authors used the number of comorbidities to adjust for confounding in their study. Residual confounding in measured covariates is a function of measurement error and model misspecification. Any restriction on the model (as imposed by controlling for the number of comorbidities instead of controlling for individual comorbidities) increases the likelihood of model misspecification and thus residual confounding. In our view the authors should have controlled for individual comorbidities rather than the number of comorbidities in this large study with strong confounding. Using the number of comorbidities would make more sense when predicting functional outcomes based on a variety of preoperative variables, rather than when assessing causality. Such a prediction model may be more informative for counseling patients prior to surgery.

The authors carefully avoided selecting results for the abstract solely based on p values, which is especially important given the difference in sample size between the hip and knee cohorts. Instead, they concentrated on the pattern for the number of metabolic abnormalities and functional outcomes, which is indeed very similar between patients with hip and knee arthroplasty. It is important to realize that reliance on $\mathrm{p}$ values to dichotomize results into positive and negative would have led to a different (and, more likely than not, wrong) conclusion in this setting. The apparent different role of hypertension in predicting poorer outcomes in patients with hip but not patients with knee arthroplasty is intriguing and needs confirmation and/or further evaluation.

The study by Gandhi and coauthors is a motivating example, and we hope that future studies from these and other authors will be able to better address our concerns and follow some of our suggestions. We need to know what works best in which patients under what circumstances in medicine $^{20}$, and nonexperimental data from retrospective and prospective, single or multicenter cohort studies are an essential piece of this process.

\section{TIL STÜRMER, MD}

Head, Pharmacoepidemiology Program, UNC Gillings School of Global Public Health, CB 7435, University of North Carolina at Chapel Hill, Chapel Hill, North Carolina 27599 USA;

\section{KLAUS-PETER GÜNTHER, MD,}

Department of Orthopaedic Surgery, University of Dresden, Dresden, Germany

Address correspondence to Dr. Stürmer;

E-mail: til.sturmer@post.harvard.edu

\section{REFERENCES}

1. Gandhi R, Razak F, Davey JR, Mahomed NN. Metabolic syndrome and the functional outcomes of hip and knee arthroplasty J Rheumatol 2010;37:1917-22.

2. Montin L, Leino-Kilpi H, Suominen T, Lepisto J. A systematic review of empirical studies between 1966 and 2005 of patient outcomes of total hip arthroplasty and related factors. J Clin Nursing 2008;17:40-5.

3. Santaguida PL, Hawker GA, Hudak PL, Glazier R, Mahomed NN Kreder HJ, et al. Patient characteristics affecting the prognosis of total hip and knee joint arthroplasty: a systematic review. Can J Surg 2008;51:428-36.

4. Jackson MP, Sexton SA, Yeung E, Walter WL, Walter WK, Zicat BA. The effect of obesity on the mid-term survival and clinical outcome of cementless total hip replacement. J Bone Joint Surg Br 2009;91:1296-300.

5. Dowsey MM, Choong P. Obesity is a major risk factor for prosthetic infection after primary hip arthroplasty. Clin Orthop Rel Res 2008;466:153-8.

6. Malinzak RA, Ritter MA, Berend ME, Meding JB, Olberding EM, Davis KE. Morbidly obese, diabetic, younger and unilateral joint arthroplasty patients have elevated total joint arthroplasty infection rates. J Arthroplasty 2009;24 Suppl:84-8.

7. Kahn R, Buse J, Ferrannini E, Stern M. The metabolic syndrome: time for a critical appraisal. Diab Care 2005;28:2289-304.

8. Meigs JB, Wilson PWF, Fox CS, Vasan RS, Nathan DM, Sullivan $\mathrm{L}$, et al. Body mass index, metabolic syndrome and risk of type 2 diabetes or cardiovascular disease. J Clin Endocrinol Metab 2006;91:2906-12

9. Grundy SM, Brewer HB Jr, Cleeman JI, Smith SC Jr, Lenfant C; American Heart Association; National Heart, Lung, and Blood Institute. Definition of metabolic syndrome: Report of the National Heart, Lung, and Blood Institute/American Heart Association conference on scientific issues related to definition. Circulation 2004;109:433-8.

10. Stürmer T, Brenner H, Koenig W, Günther KP. Severity and extent of osteoarthritis and low grade systemic inflammation as assessed by high-sensitivity C-reactive protein. Ann Rheum Dis 2004;63:200-5.

11. Stürmer T, Raum E, Buchner M, Gebhardt K, Schiltenwolf M, Richter W, et al. Pain and high-sensitivity C-reactive protein in patients with chronic low back pain and acute sciatic pain. Ann Rheum Dis 2005;64:921-5

12. Stürmer T, Buring JE, Lee IM, Gaziano JM, Glynn RJ. Metabolic abnormalities and risk for colorectal cancer in the Physicians' Health Study. Cancer Epidemiol Biomarkers Prev 2006;15:2391-7.

13. Stürmer T, Dreinhöfer K, Gröber-Grätz D, Brenner H, Dieppe P,

Personal non-commercial use only. The Journal of Rheumatology Copyright @ 2010. All rights reserved. 
Puhl W, et al. Differences in the views of orthopaedic surgeons and referring practitioners on the determinants of outcome after total hip replacement. J Bone Joint Surg Br 2005;87:1416-9.

14. Solomon DH, Avorn J, Wang PS, Vaillant G, Cabral D, Mogun H, et al. Prescription opioid use among older adults with arthritis or low back pain. Arthritis Rheum 2006;55:35-41.

15. Huch K, Müller KAC, Stürmer T, Brenner H, Puhl W, Günther KP. Sports activities 5 years after total knee or hip arthroplasty: the Ulm Osteoarthritis Study. Ann Rheum Dis 2005;64:1715-20.

16. Sun Y, Stürmer T, Günther KP, Brenner H. Reliability and validity of clinical outcome measurements of osteoarthritis of the hip and knee - a review of the literature. Clin Rheumatol 1997;16:185-98.

17. Stürmer T, Sun Y, Sauerland S, Zeissig I, Günther KP, Puhl W, et al. Serum cholesterol and osteoarthritis. The baseline examination of the Ulm Osteoarthritis Study. J Rheumatol 1998;25:1827-32.
18. Stürmer T, Günther KP, Brenner H. Obesity, overweight and patterns of osteoarthritis: the Ulm Osteoarthritis Study. J Clin Epidemiol 2000;53:307-13.

19. Stürmer T, Brenner H, Brenner R, Günther KP. Noninsulin dependent diabetes mellitus and patterns of osteoarthritis - the Ulm Osteoarthritis Study. Scand J Rheumatol 2001;30:169-71.

20. Committee on Comparative Effectiveness Research Prioritization, Institute of Medicine. Initial national priorities for comparative effectiveness research. Washington: National Academies Press; 2009:252.

J Rheumatol 2010;37:1794-6; doi:10.3899/jrheum.100701 